Protestantismo em Revista é licenciada sob uma Licença Creative Commons.

http://dx.doi.org/10.22351/nepp.v45i1.3276

\title{
COMPLEXIDADE E MUNDO COMUM: APROXIMAÇÕES DO PENSAMENTO DE MORIN E ARENDT NO ÂMBITO EDUCACIONAL
}

\author{
Complexity and Common World: Morin and Arendt Approaches to Education
}

\author{
Cassiana Everling * \\ Fábio César Junges** \\ Leandro José Kotz***
}

\begin{abstract}
Resumo
O presente artigo problematiza, inicialmente, o pensar simplificador, tendo a hiperespecialização como um dos seus elementos constitutivos. Em contrapartida, enquanto alternativa sempre aberta e em constante elaboração, é apresentado o paradigma da complexidade, tendo como principais referências o pensamento de Edgar Morin em diálogo com Hannah Arendt, apontando para a possibilidade e a necessidade de um fazer educacional voltado ao pensar o mundo comum em sua complexidade. Em um mundo cada vez mais regido pela técnica e pela tecnologia, com uma educação voltada à aquisição de competências, tendo a hiperespecialização como forma de produção de conhecimentos e de transmissão dos mesmos, pensar o mundo comum milenarmente constituído, é o desafio aqui assumido.
\end{abstract}

Palavras-chave: Complexidade. Especialização. Mundo Comum. Educação

\begin{abstract}
:
This article initially problematizes simplifying thinking, with hyperspecialization as one of its constituent elements. On the other hand, as an always open and constantly elaborated alternative, the paradigm of complexity is presented, with the main references being the thinking of Edgar Morin in dialogue with Hannah Arendt, pointing to the possibility and the necessity of an educational work geared towards thinking the world common in its complexity. In a world that is increasingly governed by technology and technology, with an education focused on the acquisition of competences, with hyperspecialization as a way of producing knowledge
\end{abstract}

* Mestre em Educação nas Ciências pela Universidade Regional do Noroeste do Estado do Rio Grande do Sul, Ijuí, Brasil. Contato: cassi1902@hotmail.com

** Doutor em Teologia pelas Faculdades EST. Pós-Doutorando em Práticas Socioculturais e Desenvolvimento Social pela UNICRUZ, com bolsa Capes e integrante do Grupo de Estudos Linguísticos - GEL/UNICRUZ, Cruz Alta, Brasil. Contato: fabiocesarjunges@yahoo.com.br

*** Doutorando em Educação nas Ciências pela Universidade Regional do Noroeste do Estado do Rio Grande do Sul, com bolsa CAPES, Ijuí, Brasil. Mestre em Educação nas Ciências pela Universidade Regional do Noroeste do Estado do Rio Grande do Sul. Contato: leandrokotz@hotmail.com 
and transmitting knowledge, to think about the common world that has been constituted for a thousand years, is the challenge assumed here.

Keywords: Complexity. Specialization. Common World. Education.

\section{Introdução}

Não poucas perspectivas de pensamento na contemporaneidade demarcam distanciamentos em relação ao pensar simplificador, especialmente no que o mesmo estabelece entre o desenvolvimento dos conhecimentos e as consequências de um pensamento circunscrito na hiperespecialização. Edgar Morin compreende que este pensar carrega certa "inteligência cega" para o todo da complexidade da realidade, aos poucos desvendada pela contemporaneidade.

A questão das novas formas de compreender os seres humanos e o mundo como um todo, manifesta, para Morin, a falta de complexidade do pensamento e uma análise que compreende que cada objeto é estudado fora da teia em que se liga. De modo análogo, Arendt propõe a adoção de uma visão mais crítica sobre os conhecimentos e o pensamento de modo geral, uma vez que a utilização errônea destes pode incorrer em graves ameaças à humanidade.

O presente artigo, neste sentido, parte do pensamento de Edegar Morin em diálogo com Hannah Arendt, com a intenção de apresentar possibilidades de um novo paradigma de conhecimento e, por consequência, de um fazer educacional na perspectiva de pensar o mundo comum em sua complexidade, sem negligenciar a necessidade do mundo dos especialistas, enquanto técnicas, instrumentos, ferramentas sempre novas, que garantem a sobrevivência dos indivíduos e das instituições num mundo assim organizado. Isso significa que a função educacional não se limita à aquisição de conhecimentos produzidos pela hiperespecialização da ciência, enquanto garantias de sobrevivência no mundo do mercado, mas em pensar o mundo comum com todas as dimensões que o envolvem, com base nas infinitas relações que se estabelecem.

\section{Mundo dos especialistas e a especialização do conhecimento}

Em termos epistemológicos e educacionais, a modernidade realiza uma verdadeira revolução copernicana no que diz respeito à capacidade humana de conhecer o mundo e de partilhar as descobertas científicas. Na modernidade se dá a constituição do humano como fundamento de suas palavras e ações, que possibilitaram a ele colocar o mundo diante de si, com condições de possibilidade de apreendê-lo em sua extensão. Com a ajuda de um bom e eficiente método ${ }^{1}$, o ser humano passou a dar novos significados ao mundo, com novos e amplos conhecimentos. Neste sentido, a modernidade se caracteriza, acima de tudo, como uma verdadeira explosão do saber.

1 DESCARTES, René. Discurso do método: meditações. São Paulo: Martin Claret, 2012. 
A modernidade abriu enormes possibilidades para conhecer o mundo e disseminar estes conhecimentos. Por força da inovação científica e tecnológica, a natureza deixa de ser um dado com leis próprias e inatingíveis, passando a ser manipulável e controlável pelo ser humano. Se antes era possível de apenas conhecer o mundo criado pelo humano, agora o ser humano passa a fazer história sobre o mundo, com poder de conhecer a própria natureza como um todo, podendo ser manipulável em sua completude. $\mathrm{O}$ alcance da velocidade científica tecnológica amplia e revoluciona o conhecimento, transpondo barreiras antes impossíveis de serem ultrapassadas.

A introdução destes, entre tantos outros novos elementos, significou o surgimento de inúmeras novas disciplinas, levando a especialização do conhecimento ou a hiperespecialização. A especialização, por um lado, possibilitou ampliar, ainda mais, os conhecimentos. Por outro lado, ampliou não somente as dificuldades de comunicação entre as diversas disciplinas, como também as dificuldades de comunicação entre as grandes áreas do conhecimento.

Efetivamente, a inteligência que só sabe separar fragmenta o complexo do mundo em pedaços separados, fraciona os problemas, unidimensionaliza o multidimensional. Atrofia as possibilidades de compreensão e de reflexão, eliminando assim as oportunidades de um julgamento corretivo ou de uma visão a longo prazo $^{2}$.

O conhecimento do mundo e sua hiperespecialização não significou, contudo, a construção de uma sociedade mais humana. Se em termos científicos e tecnológicos é possível falar de uma evolução ou ampliação progressiva da capacidade humana, ao ponto do século XX introduzir revoluções científicas, como "a atômica, a molecular, a das comunicações, a do espaço sideral e a da nanotecnologia" ${ }^{3}$, em termos humanos, no sentido de convivialidade no mundo comum, o século XX introduziu a morte e a catástrofe produzidas em larga escala, como a primeira e a segunda guerra mundial, a destruição sem igual de Hiroshima e Nagasaki, a guerra do Vietnã, etc.

A distinção realizada por Descartes entre o sujeito pensante e o conhecimento do mesmo permitiu avanços no conhecimento científico, mas teve responsabilidade também na separação entre o saber e sua reflexão, isolando os três principais campos do conhecimento científico: a física, a biologia e a ciência do homem. A crise da modernidade, enquanto desconfiança na unidade da razão e de sua capacidade de uniformização de toda a realidade enquanto objeto, requer um novo modo de conhecimento.

Para Morin, “o paradigma simplificador é um paradigma que põe ordem no universo, expulsa dele a desordem. A ordem se reduz a uma lei, a um princípio. A simplicidade vê o uno, ou o múltiplo, mas não consegue ver que o uno pode ser ao mesmo

2 MORIN, Edgar. A cabeça bem-feita: repensar a forma, reformar o pensamento. Rio de Janeiro: Bertrand Brasil, 2009. p. 14.

3 DIÁLOGO NACIONAL. O pai da bioética. Disponível em: <http://www.dialogonacional.com.br/docs/20-06-2016-artigo.pdf>. Acesso em: 18 de jul. de 2016, s/p. 
tempo múltiplo"4 ${ }^{4}$ Esse paradigma, portanto, propõe uma ordem, reduzida a um princípio. A simplicidade não possibilita que o uno seja manifesto no múltiplo e no contrário. Este princípio separa o que é unido e o que está unificado.

\section{Complexidade e mundo comum}

É a partir da questão da relação de sujeito e objeto, na sua concepção moderna, sobretudo cartesiana, que a contemporaneidade procura pensar uma racionalidade que considera a diversidade de vozes. Estes conceitos, sujeito e objeto, trabalhados de forma separada, mostram-se insuficientes em relação ao que pretendem fazer compreender. A modernidade, neste sentido, enquanto incapacidade de conciliar o único e o múltiplo, a diversidade e a unidade, consolida uma inteligência unilateral e marginalizadora.

Dadas as rupturas ocorridas no paradigma moderno, uma nova reorganização paradigmática se coloca como necessária. Quebraram-se os conceitos que sustentavam a existência dos extremos, que suprimiam a realidade num esquema simplista, compreendida como clara e evidente. Adotando o sistema como a associação de elementos distintos e a sistematização generalizada no campo fenomenal, tem-se uma teoria centrada na totalidade, formada pelo todo e não somente pelas partes distintas que a constituem.

Nesta perspectiva, não há uma relação entre os elementos diversos do saber. Por isso, o conhecimento necessita, primeiramente, de uma reflexão do complexo em si, para, a partir daí, refletir sobre seus elementos e processos definidores. A modernidade adotou uma concepção do universo como uma máquina determinista e perfeita. Na busca por uma metodologia aberta e coerente, tem-se um conjunto teórico formador de uma nova compreensão de ciência, com

um discurso multidimensional não totalitário, teórico, mas não doutrinário (a doutrina é a teoria fechada, autossuficiente, portanto insuficiente), aberto para a incerteza e a superação; não ideal/idealista, sabendo que a coisa não será nunca totalmente fechada no conceito, o mundo jamais aprisionado no discurso ${ }^{5}$.

Essa nova forma de pressupor os elementos que constituem a racionalidade da ciência, não significa a entrada num irracionalismo para contemplar elementos préconceituais que são entendidos como cotidianidade do mundo. O que há, segundo Rouanet, é uma tarefa de desmascaramento de uma razão unilateralista, que não se constitui simplesmente em exaltar "faculdades mais 'altas' que a razão, que deem acesso a verdades vedadas ao pensamento discursivo" 6 .

A complexidade do pensamento atual requer que o paradigma moderno, caracterizado pela disjunção, redução e simplificação, seja questionado em seus

\footnotetext{
MORIN, Edgar. Introdução ao pensamento complexo. Porto Alegre: Sulina, 2011. p. 59.

MORIN, 2011, p. 49.

6 ROUANET, Sérgio Paulo. As razões do iluminismo. São Paulo: Companhia das Letras, 1987. p. 272.
} 
fundamentos. Pela antropologia, por exemplo, ao invés da hiperespecialização, tem-se uma perspectiva que condensa uma metodologia aberta e específica. Na consolidação da scienza $n$ nova ${ }^{7}$, os conceitos clássicos são reconstituídos em termos antagônicos, contraditórios e complementares, propondo uma visão mais universalizada.

Isso significa uma viragem paradigmática, não apenas no sistema de pensamento, como em toda a sociedade, uma vez que a pedra angular de qualquer sistema do pensamento, afeta todas as dimensões da sociedade. A partir destas considerações, tem-se uma noção da amplitude e da complexidade requerida em uma reforma paradigmática: sob um viés simplista há a necessidade da mudança de um raciocínio na sua base e das relações associativas e repulsivas estabelecidas por conceitos iniciais. A maior problemática está na mudança a ser feita na pedra angular sobre a qual todo o intelecto é edificado. Essa dificuldade decorre da ruptura feita em toda a estrutura de ideias que regem a forma de pensar.

Como alternativa, Morin desenvolve uma concepção paradigmática da complexidade, mostrando as diferenças para com o paradigma simplificador. O paradigma da complexidade não fica restrito às novas concepções científicas. Ele está muito presente no próprio cotidiano, desde uma simples partícula até as relações sociais mais complexas. Tendo a premissa da constância entre a ordem e a desordem do universo, é lícito afirmar que, mesmo antagônicas, elas cooperam para a manutenção de uma organização no universo.

Ora, os problemas essenciais nunca são parceláveis, e os problemas globais são cada vez mais essenciais. Além disso, todos os problemas particulares só podem ser posicionados e pensados corretamente em seus contextos; e o próprio contexto desses problemas deve ser posicionado, cada vez mais, no contexto planetário ${ }^{8}$.

Neste sentido, "a complexidade da relação ordem/desordem/organização surge, pois, quando se constata empiricamente que fenômenos desordenados são necessários em certas condições, em certos casos, para a produção de fenômenos organizados, os quais contribuem para o crescimento da ordem" ${ }^{\prime \prime}$. Sob uma análise do universo no olhar tempo e espaço, há algo que foge de ambos: a complexidade, mas isso não anula a existência dos mesmos, pois o tempo e o espaço presenciam-se onde não se pode vencer uma contradição. Portanto, "é exatamente o que dizia Heráclito: há a harmonia na desarmonia e vice-versa"10.

O conceito de complexidade dá uma noção de dificuldade, mesmo que a complexidade esteja ligada à desordem ou simplesmente a contradições lógicas. Uma contradição não é de forma alguma um erro, é o ápice de entendimento da realidade, daí a dificuldade no entendimento. Com isso, tem-se a distinção entre complexidade e completude ${ }^{11}$. Completude é o resultado de uma visão universal que não ignora nada, vêse tudo correlacionado. Ver o todo possibilita o caráter multidimensional da realidade, e define como imparcialidade uma visão especializada. Então, surge a relação entre

\footnotetext{
MORIN, 2011, p. 48-49.

MORIN, 2009. p. 13-14.

MORIN, 2011, p. 63.

10 MORIN, 2011, p. 64.

11 Cf. MORIN, 2011, p. 68-69.
} 
completude e complexidade. Compilação, entretanto, não é uma esfera concomitante com a complexidade e sim um de seus constituintes.

É possível compreender a complexidade na relação entre produtor e produto: “os indivíduos produzem a sociedade que produz os indivíduos. Somos ao mesmo tempo produtos e produtores"12. Na sequência desta relação surgem as três causalidades: a causalidade linear, se aplicado um processo de transformação sobre uma matéria-prima, então será produzido um objeto de consumo; a causalidade circular retroativa, é a ação de regulação feita pelo produtor buscando mais, ou melhor, produto invariavelmente das condições externas; e na causalidade recursiva há uma dependência intercalada entre os produtos e os produtores ${ }^{13}$. A auto-eco-organização está associada a um princípio hologramático, cada parte possuindo uma teia de informações que estão contidas no todo, do qual fazemos parte e está no nosso espírito.

A ciência funda-se, portanto, sobre a própria mutabilidade. Portanto, o científico se dá na construção com o não científico, em que um não anula o outro, mas ambos se potencializam. A partir destas noções conclui-se que a ciência jamais encontra de modo absoluto o que procura, ela descobre uma chave de uma nova problemática. Em uma ciência ou empreendimento qualquer, é a organização dos níveis que determinam a capacidade de redução, contudo, não há como reduzir a essência da complexidade.

Por isso, a verdade nunca é o resultado de causalidade direta. Sempre há a necessidade de organização para que o previsível tenha um resultado a partir do reconhecimento aleatório feito pela auto-organização. A ordem, a desordem e a organização não possuem uma ligação direta e, portanto, nenhuma das duas é majoritária em relação à outra. A necessidade básica para a existência da informação é o processo de comunicação entre os seres vivos, portanto, a vida. O mistério está mais presente em nós mesmos do que no mundo exterior, revelando a necessidade da separação entre o cognoscente e o cognoscível.

\section{Conhecer e renovar o mundo comum}

Conforme o exposto acima, há mais formas de racionalidade que a modernidade apresenta a partir da dualidade sujeito e objeto e que, em boa medida, ainda é orientadora de diversas ciências, principalmente das ciências naturais e, inclusive, do campo educacional. Não se trata de dizer que a modernidade não possui validade no que diz respeito à educação. Trata-se de afirmar, acima de tudo, que ela não congrega o todo da racionalidade do conhecimento. Para Morin, "o mundo está no interior de nossa mente que está no interior do mundo. Sujeito e objeto nesse processo são constitutivos um do outro"14. Desta forma, evita-se o erro de fechamento e restrição dos conceitos fundamentais da ciência e da filosofia em compreensões unilaterais.

O sujeito deve permanecer aberto, desprovido de um princípio de decidibilidade nele próprio; o objeto deve permanecer aberto, de um lado sobre o sujeito, de outro

\footnotetext{
MORIN, 2011, p. 74.

Cf. MORIN, 2011, p. 86-87.

4 MORIN, 2011, p. 64.
} 
lado sobre o seu meio ambiente, que, por sua vez, se abre necessariamente e continua a abrir-se para além dos limites do nosso entendimento ${ }^{15}$.

A perspectiva aqui adotada, portanto, se distancia das preocupações epistemológicas da modernidade, na sua relação com a educação. De certa forma, a proposta adotada se caracteriza como certo recuo, isto é, das condições de possibilidade de conhecer este mundo para o pensar o mundo humano, que apesar de educacionalmente ainda se situar, em boa medida no paradigma simplificador, com a chegada dos novos, há sempre a possibilidade de instaurar a novidade e a imprevisibilidade. Portanto, a preocupação gira sobre "o papel que a educação desempenha em toda a civilização, ou seja, sobre a obrigação que a existência de crianças impõe a toda a sociedade humana"16.

A educação, confundida com aprendizagem, volta-se cada vez mais para o mundo da técnica e da tecnologia. A aquisição de competências vem sendo a principal referência no que diz respeito ao fazer educacional. Diante da rápida renovação do mundo tecnológico, a escola e a universidade fazem todo o esforço possível para acompanhar as constantes transformações. Para dar conta destas demandas, a hiperespecialização é a alternativa que se apresenta, carregando consigo "[...] uma forma particular de abstração" 17 . O mundo dos especialistas é, portanto, o mundo do pesquisador e também do docente.

O conhecimento especializado acaba mutilando a realidade, por abstrair elementos particulares de uma realidade complexa, simplificando-a. A hiperespecialização é, em grande medida, uma visão míope da realidade, por não considerar o global nem mesmo o essencial da realidade. "A cultura científica e técnica disciplinar parcela, desune e compartimenta saberes, tornando cada vez mais difícil a sua contextualização"18. Estes conhecimentos compartimentados acabam sendo importantes na profissionalização dos estudantes, mas não dão conta da tarefa educacional de introduzi-los no mundo global.

A educação, contudo, ao contrário da aprendizagem, precisa ter um final previsível. Em nossa civilização esse final coincide provavelmente com o diploma colegial, não com a conclusão do curso secundário, pois o treinamento profissional nas universidade ou cursos técnicos, embora sempre tenha algo a ver com a educação, é, não obstante, em si mesmo uma espécie de especialização. Ele não visa mais introduzir o jovem no mundo como um todo, mas sim em um segmento limitado e particular dele ${ }^{19}$.

Nesta perspectiva, saberes milenarmente constituídos, com o esforço de muitos que nos antecederam, revelam-se como obsoletos. O que não pode ser imediatamente aproveitado e colocado a serviço do mercado de trabalho tem perdido seu valor. A escola e a universidade já não são mais os lugares por excelência de apresentação da cultura,

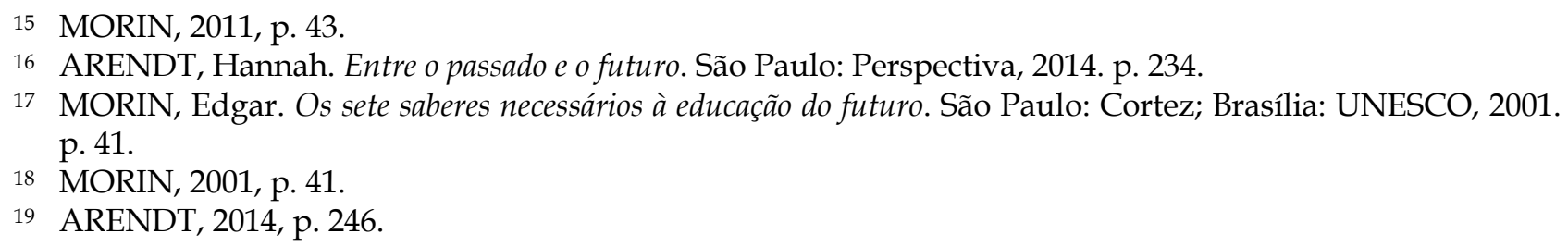


símbolos, tradições e saberes historicamente elaborados, com acertos e erros, próprios da condição humana. O interesse educacional se volta para um futuro em aberto, desconhecido, imprevisível, em detrimento e desencanto pelas tradições históricas que nos constituíram e nos constituem. Esquece-se, neste sentido, que

a compreensão, diferentemente da informação correta e do conhecimento científico, é um processo complexo que nunca gera resultados inequívocos. É uma atividade interminável por meio da qual, em constante mudança e variação, chegamos a um acordo e a uma conciliação com a realidade, isto é, tentamos sentir o mundo como nossa $\operatorname{casa}^{20}$.

Sentir o mundo como nossa casa significa, antes de tudo, compreender que o mundo tem muito mais a nos oferecer do que apenas artifícios técnicos que garantem a sobrevivência dos recém-chegados no mundo. Significa compreender, para além dos conhecimentos científicos e das constantes informações proporcionadas pelas novas descobertas tecnológicas, o que constitui o mundo humano, enquanto sentidos e significados constituídos ao longo da história. Significa “[...] reconhecer-se em sua humanidade comum e ao mesmo tempo reconhecer a diversidade cultural inerente a tudo que é humano"21. Apesar de ser um processo sempre aberto, indefinido, infindável, com resultados totalmente imprevisíveis, compreender o mundo comum é uma das únicas formas possíveis de se situar no mundo e, por extensão, de apresentar este mundo aos novos.

Compreender é infindável e, portanto, não pode gerar resultados definitivos. É a maneira especificamente humana de viver, pois todo indivíduo precisa se sentir conciliado com o mundo onde nasceu como estranho e onde sempre permanece como estranho, na medida de sua singularidade única. A compreensão começa com o nascimento e termina com a morte ${ }^{22}$.

Uma das funções educacionais, especialmente numa perspectiva filosófica aqui assumida, é de apresentar reflexões e questionamentos em relação ao que é assumido como dado. O mundo humano não se resume ao mundo da técnica e da tecnologia. Uma diversidade de dimensões atualmente, negligenciadas ou deixadas de lado, fazem parte das formas de organização do nosso mundo. Sem ignorar que o mundo dos especialistas faz parte do atual estado de organização de vida, o mundo humano não se resume na aquisição de especialidades.

\section{Considerações finais}

A chegada dos novos, portanto, coloca sempre novas questões à educação e, inclusive, faz com que o fazer educacional seja sempre necessário. A relação dos novos com

20 ARENDT, Hannah. Compreender: formação, exílio e totalitarismo (ensaios). São Paulo: Companhia das Letras; Belo Horizonte: UFMG, 2008. p. 330.

21 MORIN, 2001, 47.

22 ARENDT, 2008, p. 331. 
o mundo em geral e com a educação em particular se dá em duas direções. Em primeiro lugar, é preciso proteger os recém-chegados deste mundo que lhes é estranho e até mesmo perigoso. Em segundo lugar, os recém-chegados necessitam ser inseridos neste mundo cultural, simbólica e historicamente constituído. Neste caso, a presença dos novos no mundo torna a educação sempre necessária e atual, ultrapassando a ideia de simples aquisição de competências e conhecimentos científicos.

Como dizia magnificamente Durkheim, o objetivo da educação não é o de transmitir conhecimentos sempre mais numerosos ao aluno, mas o "de criar nele um estado interior e profundo, uma espécie de polaridade de espírito que o oriente em um sentido definido, não apenas durante a infância, mas por toda a vida". É justamente, mostrar que ensinar a viver necessita não só dos conhecimentos, mas também da transformação, em seu próprio ser mental, do conhecimento adquirido em sapiência, e da incorporação dessa sapiência para toda a vida ${ }^{23}$.

A apresentação deste mundo aos novos vai além da apreensão de conhecimentos científicos e tecnológicos, de competências profissionais e especializadas proporcionadas pela fragmentação dos saberes. A educação, antes de oportunizar a aquisição de competências que garantem a sobrevivência dos novos no mundo, tem como função primeira introduzir os recém-chegados no mundo simbolicamente elaborado, em todos os seus sentidos e dimensões. Diferente da realidade dos demais seres vivos, o ser humano, além da necessidade de sobrevir no mundo, tem a necessidade de se inserir num mundo já constituído e que está em constante constituição.

A primeira coisa que a educação transmite a cada um dos seres pensantes é de que não somos únicos, que nossa condição implica o intercâmbio significativo com outros parentes simbólicos que confiram e possibilitam nossa condição. A segunda coisa, por certo, não menos relevante, é que não somos os iniciadores da nossa linhagem, que aparecemos no mundo em que a marca humana já está vigente de mil modos e existe uma tradição de técnicas, mitos e ritos da qual vamos fazer parte e na qual também nos vamos formar ${ }^{24}$.

A educação tem a ver, antes de tudo, com apresentação deste mundo aos novos, tal como ele é, bem como em abrir espaço para que estes possam empreender alguma novidade, no sentido de repensar paradigmas simplificadores e reducionistas da vida humana. Neste sentido, os conhecimentos a serem adquiridos não se reduzem a garantia da sobrevivência do ser humano no mundo do mercado de trabalho, numa sociedade cada vez mais fragmentada, simplificada e reducionista, em constante evolução tecnológica. Afinal de contas, a compreensão do mundo em que o ser humano se encontra inserido é condição de possibilidade de empreender um mundo diferente.

\section{Referências}

23 MORIN, 2009, p. 47.

24 SAVATER, Fernando. O valor de educar. São Paulo: Planeta, 2012. p. 38. 
ARENDT, Hannah. Compreender: formação, exílio e totalitarismo (ensaios). Trad. Denise Bottman. São Paulo: Companhia das Letras; Belo Horizonte: UFMG, 2008.

ARENDT, Hannah. Entre o passado e o futuro. Trad. Mauro W. Barbosa. São Paulo: Perspectiva, 2014.

DESCARTES, René. Discurso do método: meditações. Trad. Roberto Leal Ferreira. 2. ed. São Paulo: Martin Claret, 2012.

DIÁlOGO NACIONAL. O pai da bioética. Disponível em: < http://www.dialogonacional.com.br/docs/20-06-2016-artigo.pdf>. Acesso em: 18 de jul. de 2016,

MORIN, Edgar. A cabeça bem-feita: repensar a forma, reformar o pensamento. Trad. Eloá Jacobina. 16. ed. Rio de Janeiro: Bertrand Brasil, 2009.

. Introdução ao pensamento complexo. Trad. Elaine Lisboa. 4. ed. Porto Alegre:

Sulina, 2011.

Os sete saberes necessários à educação do futuro. Trad. Catarina Eleonora F. da Silva e Jeanne Sawaya. 3. ed. São Paulo: Cortez; Brasília: UNESCO, 2001.

ROUANET, Sérgio Paulo. As razões do iluminismo. São Paulo: Companhia das Letras, 1987.

SAVATER, Fernando. O valor de educar. Trad. Monica Stahel. 2. ed. São Paulo: Planeta, 2012. 